E3S Web of Conferences 1, 06001 (2013)

DOI: $10.1051 / \mathrm{e} 3$ sconf/20130106001

(C) Owned by the authors, published by EDP Sciences, 2013

\title{
Mercury in Some Lakes of Gold Mining Area of the Southern Ural
}

\author{
Y. G. Tatsy
}

Vernadsky Institute of Geochemistry and Analytical Chemistry of the Russian Academy of Science, 19 Kosygin St., Moscow 119991, RUSSIA, tatsy@geokhi.ru

\begin{abstract}
The mercury content in bottom sediments of Kalkan Lake, of the Uchala district, the Southern Ural. It was assumed that high concentrations of mercury in fish due to pollution of bottom sediments as a result of amalgamation at developing of gold placers. Detailed study of distribution of different elements in sediments show close association $\mathrm{Hg}$ with the chalcophylic elements, whose anomalies do not have technogenic nature. Association of mercury with the elements-companions of gold placers is evidence of basic contribution of natural mercury to its anomalous accumulation in sediments and fish. This is result of steady long-term natural mercury pollution.
\end{abstract}

Key words: mercury pollution, gold mining, fish, bottom sediment

\section{Introduction}

The intensive mercury pollution of the environment in the gold mining regions is one of the global ecological problems (Lacerda 1998). The mercury use for these purposes in USSR was officially forbidden in 1990. However its intensive and long use has resulted in significant mercury pollution of gold mining regions. These mining activities in the Ural have more than a 250year's history. Placer and ore gold deposits were mined in the watersheds of some lakes of the Uchala district for a long time (Kutliakhmetov 2002). Therefore, the relevance of a possible assessment of mercury pollution in this area does not cause doubts.

An important property of mercury is its ability for bioaccumulation in aquatic trophic chains, which leads to a dangerous concentration of $\mathrm{Hg}$ in predatory fish. Therefore the study of the content of $\mathrm{Hg}$ in fish is the required part of any environmental study of regions with the possible mercury pollution. On this reason the mercury content in the perch (Perca fluviatilis) was used as an assessment of mercury contamination of some Urals lakes (Fig.1, Baranov et al., 2004). The lowest average concentration was determined in fish from Karagaikul Lake - $69.7 \mu \mathrm{g} / \mathrm{kg}$ (wet weight), the increased content from Urgun Lake $(127.8 \mu \mathrm{g} / \mathrm{kg})$ and very high content from Kalkan Lake $(565 \mu \mathrm{g} / \mathrm{kg})$. The mercury concentrations in three specimens from the Kalkan Lake exceeded the maximum permissible level (MPL $=600$ $\mu \mathrm{g} / \mathrm{kg}$ ) and in two samples were close to it.

The purpose of this work is the explanation the high mercury content in Kalkan Lake.

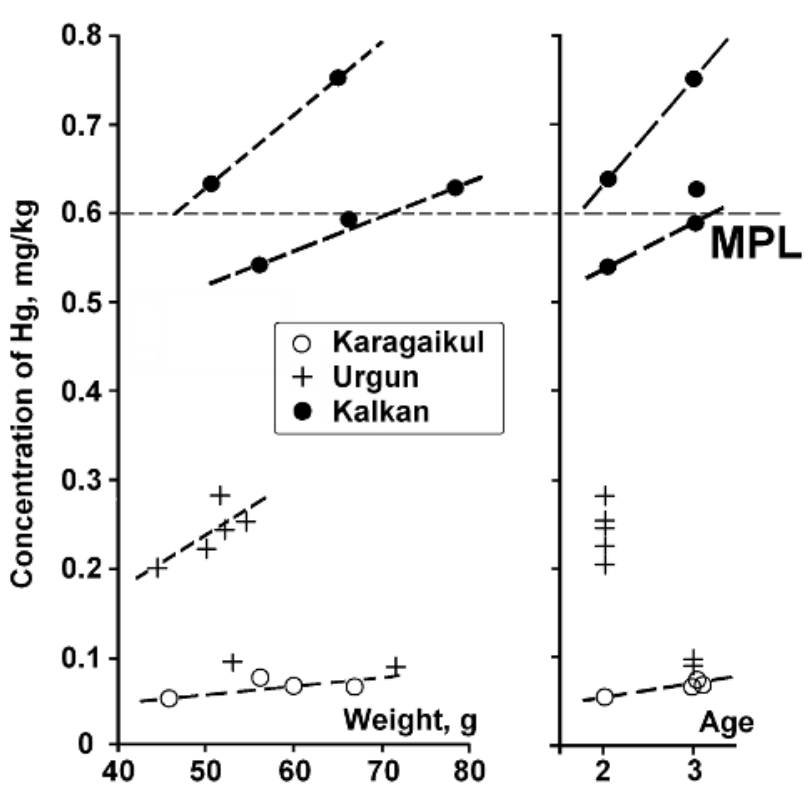

Fig. 1. Mercury concentration in perch from Karagaikul, Urgun and Kalkan Lakes

\section{Materials and Methods}

The lakes under investigation were located within the eastern slope of the South Urals in the transitional foothill landscape. They all relate to small lakes (with area of water surface up to $10 \mathrm{~km}^{2}$ ). 

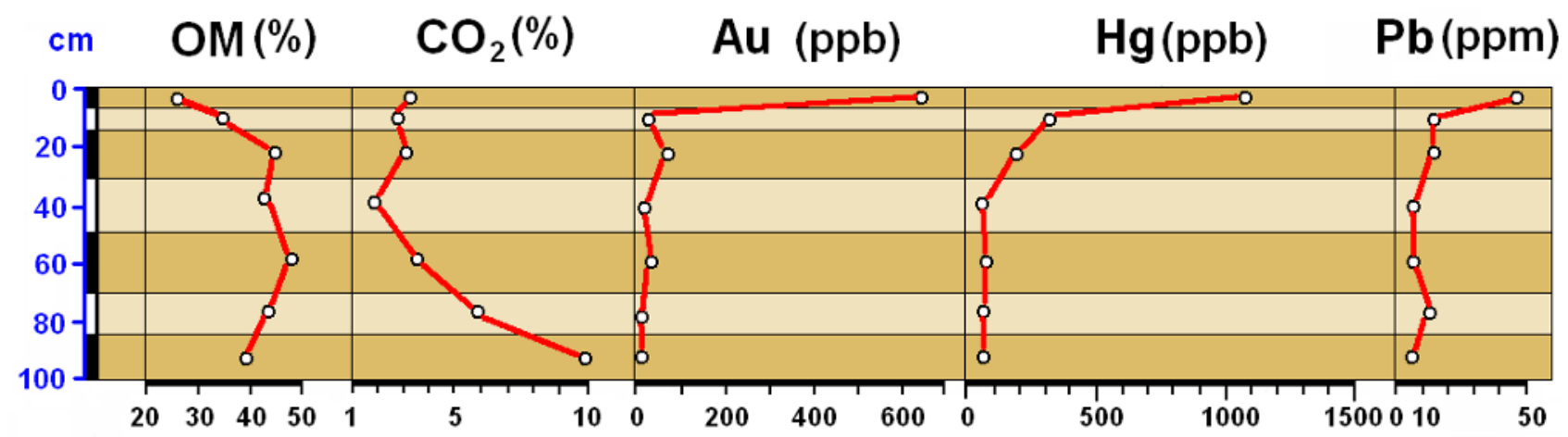

Fig. 2. Distribution of organic matter, $\mathrm{CO}_{2}, \mathrm{Au}, \mathrm{Hg}$ and $\mathrm{Pb}$ in sediment core

For explaining the morphology of lake basins and thickness of bottom sediments the method of geoacoustic (geo-locating) data were used (echo depth sounder "Fishin Buddy II" (USA).

The Karagaikul Lake was chosen as the background lake since there were not any gold ore deposits and placers mining into its watershed.

The main objects of study were bottom sediments. The sediment's thickness at depths more than $2-3 \mathrm{~m}$ is usually $1.5-2 \mathrm{~m}$, rarely up to $2.5 \mathrm{~m}$. Sediment sampling tube $(\varnothing 40 \mathrm{~mm})$ allows to take the continuous unviolated columns (cores) with length up to $1 \mathrm{~m}$. The cores were sliced into sections of $10-30 \mathrm{~cm}$ according to colour and texture and dried in air. The testing of stream which falls in Kalkan Lake was carried out for identification sources of gold and mercury in lake sediments. All were sampled 600 lake sediments, 65 stream sediment and 47 rocks and soils.

All samples were analyzed by semiquantitative AES and NAA for 36 elements. Mercury have been determined by pyrolytic CV-AAS with amalgamation

The Kalkan Lake was chosen as the base lake of this research. More than $65 \%$ of all samples were collected from this lake and its watershed.

\section{Results and Discussion}

During the study of trace elements distribution in sediments were discovered a seasonal (summer-winter) variation of concentrations and accumulation of most elements in surface active layer (SAL). Differences in the contents of $\mathrm{Hg}$ in winter and summer samples were 3-8 times. Similar, but less contrast seasonal changes observed for most other elements. Analysis of the results has shown persistently high accumulation chalcophylic elements (Hg, Pb, Zn, Ag) in SAL (Fig. 2). Significant changes in accumulation rate also occur by season. Maximum accumulation of $\mathrm{Hg}$ occurs in summer.

Analysis of lake sediment cores has shown the maximal contents of $\mathrm{Hg}$ (more than $30 \mathrm{mg} / \mathrm{kg}$ ) in sediments near Zhuravka River's mouth (background level $0.008 \mathrm{mg} / \mathrm{kg}$ ). Some cross section analysis of sediments were made to study the mercury distribution along the Kalkan Lake.

Mercury has demonstrated anomalies of maximum intensity and almost continuous distribution of anomalous fields in SAL on basin of lake. Its contents into SAL reach $20 \mathrm{mg} / \mathrm{kg}$ (background - $0.04 \mathrm{mg} / \mathrm{kg}$ ), i.e. the contrast of $\mathrm{Hg}$ anomalies reaches 500 and above. The structure of the anomalous field of mercury is analogous to anomalous field of $\mathrm{Au}$.

The anomalies of gold in SAL cover about $80 \%$ of the lake area. Maximum concentration of gold (1.2 $\mathrm{mg} / \mathrm{kg}$ ) was found in the sand at the mouth of the stream Zhuravka. Comparison of anomalies $\mathrm{Au}$ and $\mathrm{Hg}$ shows clearly the structural, spatial and paragenetic link of these two metals. Value of $\mathrm{Hg}$ as satellite $\mathrm{Au}$ is obvious.

The gold mineralization of sediments proven in 1903-1906 for Kalkan Lake and a large gold placer was mined in the end of XIX century in the valley of small river Zhuravka flowed in the Kalkan Lake. The gold placers located on catchment areas of lake and also directly in the lake have been mined at the same time. On this reason the high mercury contents in fish from Kalkan Lake at first were explained the use of mercury for gold extraction and technogenic pollution of bottom sediments. However, testing of sediment along Zhuravka stream did not confirm the expected intensive flows of $\mathrm{Au}$ or $\mathrm{Hg}$.

In addition, detailed study of distribution of different elements in sediments not confirmed this assumption. Moreover, close association $\mathrm{Hg}$ with the chalcophylic elements, whose anomalies do not have technogenic nature, enters into contradiction with this assumption.

The anomalies of $\mathrm{Hg}$ and $\mathrm{Au}$ are closely associated with anomalies of $\mathrm{Pb}, \mathrm{Zn}, \mathrm{Ag}, \mathrm{Co}, \mathrm{Sn}$ forming polyelement anomalous geochemical fields. Besides gold, mercury is especially closely connected to lead. The characteristic feature of distribution of $\mathrm{Hg}$ and other elements in sediment profiles is their contrast accumulation in SAL, which is a complex geochemical barrier on the border of water - sediment. Polyelement fields of gold and its elements-companions in SAL are 


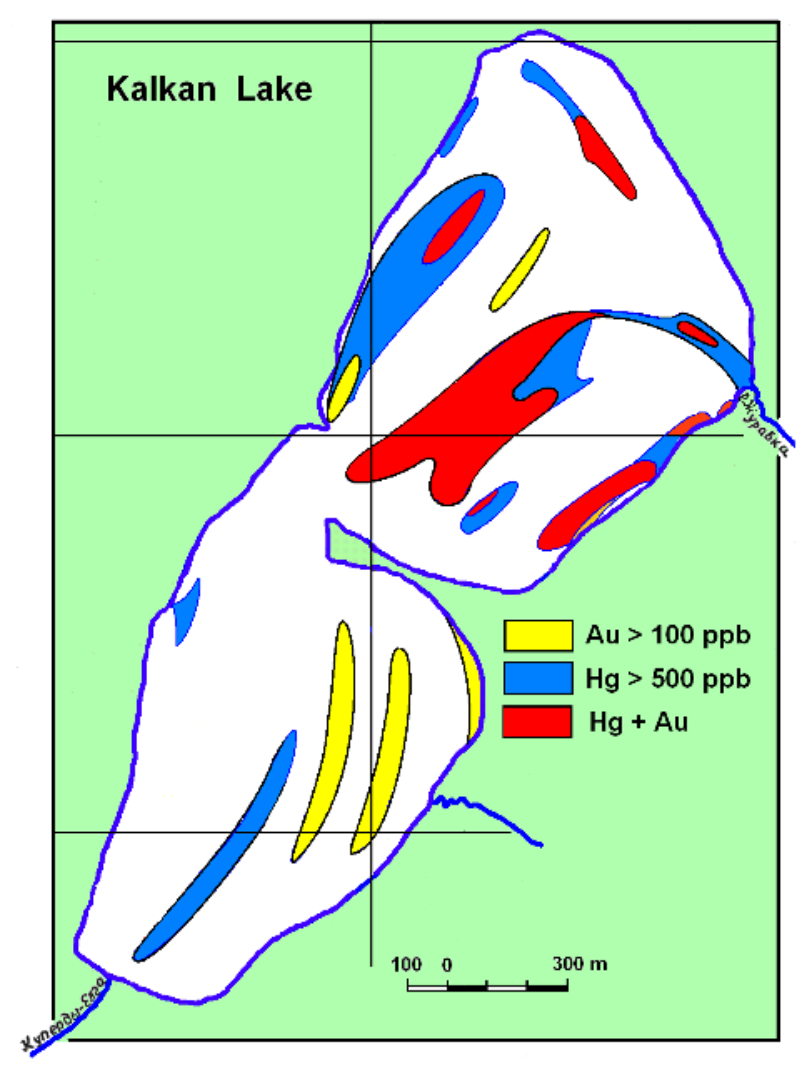

Fig. 3. High contrasting anomalies of $\mathrm{Hg}$ and $\mathrm{Au}$ in surface active layer of sediments in Kalkan Lake

spatially belongs to paleobeds and partially terrigenous terraces. These fields are interpreted as indicators of underwater gold placers, which were earlier mined in Kalkan Lake. Close association of mercury with the elements-companions of gold placers is evidence of basic contribution of natural mercury (not introduced from outside) to its anomalous accumulation in sediments and accordingly in fish. High mercury level in ecosystems of such lakes is caused basically by increased mercury level in ores of gold and other metals deposits located on catchment areas, i.e. $\mathrm{Hg}$ in such lakes has basically natural origin.

\section{Conclusion}

The obtained spatial distribution of $\mathrm{Au}, \mathrm{Hg}$ and other elements in the bottom sediments of the Kalkan Lake show that $\mathrm{Hg}$ in such lakes has basically natural origin. High mercury levels in sediments are interpreted as indicators of underwater gold placers.

Most of the elements are accumulated in the upper active layer of sediment and their accumulation rate depends on the time of year and weather conditions.

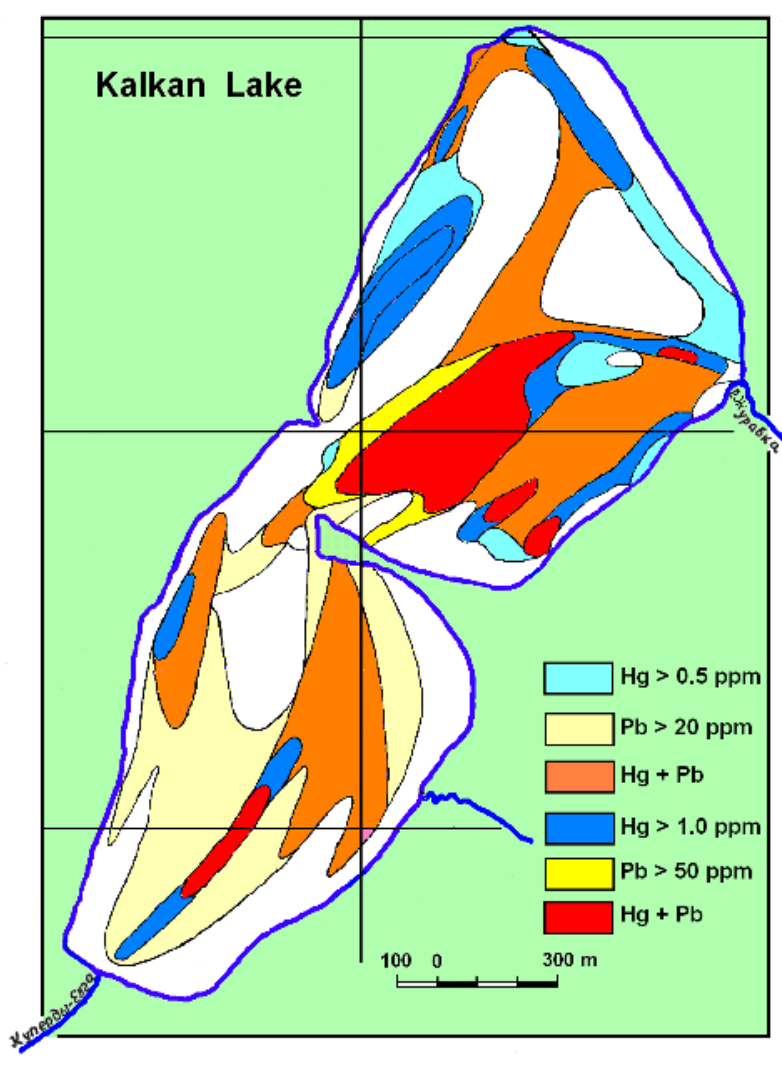

Fig. 4. High contrasting anomalies of $\mathrm{Hg}$ and $\mathrm{Pbu}$ in surface active layer of sediments in Kalkan Lake

The Kalkan Lake is characteristic lake which allows to study behavior of mercury in areas of old gold mining. Lakes of such type are some kind of mercury source.

These lakes are of interest from the point of view of steady long-term natural mercury pollution.

\section{References}

Baranov E.N., Laperdina N.G., Tatsy Y.G. Mercury in some lakes of the Southern Ural. Influence of former gold mining. RMZ - Materials and Geoenvironment 2004; 51: 9-11.

Lacerda L.D. de, Salomons W. Mercury from gold and silver mining: A chemical time bomb? Berlin: Heidelberg, 1998, 146 p.

Kutliakhmetov A.N. Mercury pollution of the landscapes due to mining enterprises of Bashkirian Transural. Ph.D. Thesis. Ecaterinburg, 2002. 25 p. (in Russian). 